\title{
English Online Tutoring: A Study of University Students Learning to Teach Junior High Students
}

\author{
Hung-Hsuan $\mathrm{KaO}^{1}$, Chiou-Hui Chou ${ }^{2 *}$
}

\author{
${ }^{1}$ Jinwen University of Science and Technology, 99 Anzhong Rd., Xindian Dist., New Taipei City 23154, TAIWAN \\ ${ }^{2}$ National Hsinchu University of Education, 521 Nanda Road, Hsinchu, 300, TAIWAN \\ *Corresponding Author: joyce@mail.nhcue.edu.tw
}

Citation: Kao, H.-H., \& Chou, C.-H. (2018). English Online Tutoring: A Study of University Students Learning to Teach Junior High Students. Mediterranean Journal of Social \& Behavioral Research, 2(1), 3-7. https://doi.org/10.30935/mjosbr /8381

\begin{abstract}
Since 2006, the Ministry of Education in Taiwan has collaborated with universities to launch synchronous online one-on-one tutoring in afterschool programs at rural schools to provide educational e-learning opportunities. The purpose of implementing the free online tutoring program is further to bridge the gap of students' academic performance and the gap of learning opportunities between urban and rural schools. This study investigated how EFL university students learned to tutor junior high students English in an online afterschool program. Twenty-two students participated in this tutoring program. The research data were collected from the tutors' reflective journal notes after each tutoring session, meeting discussions, and the post-project survey. Research results showed this tutoring project inspired the tutors to be teachers, to develop their sense of responsibility, to be independent, and to learn to care students. This study then offers pedagogical implications and suggestions for researchers and educators interested in researching into this topic.
\end{abstract}

Keywords: EFL, online tutoring, synchronous online tutoring

Received: 22 Oct. 2017 Accepted: 5 Mar. 2018

\section{INTRODUCTION}

The application of E-learning to improve education is immense in the 21 st century. The potential for online learning programs offers learners great opportunities to learn with more convenience. Online tutoring is one of the prevalent educational tools around the world. Since 2006, the Ministry of Education in Taiwan has launched synchronous online tutoring in afterschool programs at rural schools to provide educational e-learning opportunities. The purpose of implementing the online tutoring program is to bridge the gap between urban and rural schools regarding academic performance and learning opportunities. In 2010, in order to help more students with their academic learning, the MOE in Taiwan started to include students coming from low socio-economic families in the online tutoring project. In 2014, there are about one thousand students from twentyfour universities participating in the online tutoring project, tutoring elementary and junior high students in the subjects of Mathematics, Chinese, and English.

In this study, we seek to understand how university students provide help to their tutees and how the university students learn from the tutoring experience. Research on the tutoring impacts on university students is scant. Thus, this study sets out to explore the relevant issues.
Purpose of the Study

The focus of this study is to describe university students' tutoring experiences as they interacted with the junior high tutees in a one-onone online tutoring program and it extends to investigate their frustrations and triumph. Examining their online tutoring perceptions can help researchers better understand how to strengthen instruction for online tutors.

In this study, we chose to focus on the tutors' success and frustrations. We posed the following questions: (1) What are the tutoring impacts on university students? (2) What are the frustrations that university students encountered? Examining where the tutors experienced success and difficulty allows teacher educators to better understand how to support future tutors and organize a fine-tune program to further illuminate this tutoring education.

\section{LITERATURE REVIEW}

Today, e-learning platforms have been advanced not only to provide synchronous audio interaction but also synchronous face-toface interaction. The face-to-face function offers opportunities for learners to have actual interactions to practice their English skills in a more authentic and communicative setting. It allows for real-time oral 
communication among students and between students and tutors (Hampel \& Hauck, 2004).

In the synchronous online tutoring program, the learners are immersed in a natural language learning environment. They can practice oral skills with the tutor in authentic communicative settings. It can also help expand learners' exposure to the target language through real-time interaction. When they engage in interaction, they then receive input, feedback, and opportunities to produce modified output.

The main role of the online tutor is that of educational facilitator: to contribute specialist knowledge (Ryan, Scott, Freeman, \& Patel, 2000). Just as Lentell (2003) states, tutors "facilitate and guide the learning of their students so that the students gain knowledge and understanding" (p. 67). In order to achieve this, tutors have to develop and practice a multitude of skills and strategies. Thus, according to Lentell, the typical duties of a distance education tutor include ensuring students have grounding in the subject and providing students with academic support in the subject matter.

Simpson (2002) describes two broad areas of tutor support: academic and non-academic. Academic (or tutorial) support deals with supporting students with the cognitive, intellectual and knowledge issues of specific courses. This includes developing general learning skills academic and non-academic and literacy. Non-academic (or counselling) support is the support of students in the affective aspects of their studies.

To sum up, the above literature highlights the characteristics and functions of the online tutors in facilitating the tutees to learn. It serves as the framework for guiding the present research.

\section{METHODOLOGY}

\section{The Project}

The project was funded by the Ministry of Education, Taiwan. There are 22 English tutors, participating in this present research. The one-on-one synchronous tutoring session was on every Tuesday from 18:00-19:30. Tutors were delivering the lesson in a language lab and the tutees were receiving the tutoring in their school lab. The program lasted for ten weeks in a semester. A face-to-face welcoming party and a field trip were arranged for the tutees and tutors to get to know each other.

The e-learning platform used was JoinNet. Before the project, tutors were given workshops on how to use the platform to deliver online lessons and how to design learning materials. On JoinNet, users can communicate and see each other via web cameras. They can also communicate in real time by typing messages on the whiteboard and sending messages or files. They can also share and view the same websites.

\section{Data Collection}

The study used a combination of quantitative and qualitative methods. The data were collected from tutors' reflective journal writing after each tutoring session, discussion data from two face-to-face meeting sessions, and a questionnaire, delivered at the end of the project. The questionnaire consisted of open-ended questions and twenty-two Likert-type questions on a 5-point scale (5: strongly agree, 4: agree, 3: neutral, 2: disagree, 1: strongly disagree).
During the final meeting sessions, the researcher posed the following questions for the tutors to reflect: You have worked with your tutee for two months. Think about these questions: How much do you understand your tutee? How is/she learning in the tutoring session? How are you working with him/her? How do you intend to help him/her? Have you tried to use any strategies/plans to encourage/help your tutee to learn?

\section{Data Analysis}

The results from the university students' surveys, reflective journal writing, and discussion data were analyzed quantitatively and qualitatively to determine their perceptions of participating in this tutoring project. We integrated findings from the different data sources to identify themes regarding the nature, quality, and perceived impact. Using a constant comparative approach (Lincoln \& Guba, 1985) to analyze the data, we began by independently coding data for each tutor based on our research questions. We examined the tutors' written responses to develop categories to identify common themes: teaching strategies, learning to be a teacher, caring tutees, and feeling frustrated as well feeling triumphant. Then, working together in analysis, we refined our categories as we presented in the findings and discussion sessions. Thus, we first reported the tutors' perceptions of the tutoring program and extended to the impacts of the tutoring program on them.

\section{FINDINGS AND DISCUSSIONS}

\section{The Quantitative Data}

All the questions and the responses are listed in Appendix A. All of the items receive the means above 4 , except for item 2 to 8 and item 20 . First, Item 1 and Item 22 ask about how the tutoring program helped them learn to teach English overall. The means of the two items are 4.53 and 4.37. It appears that the tutors learned about teaching skills in this tutoring program.

Second, Item 2 to Item 8 ask about tutors' perceptions about their teaching skills and the materials they prepared, the means of the seven items are below 4. It seems that the tutors did not feel satisfied at the two aspects. It is only this aspect that the tutors thought they were not performing well and needed to learn more. Third, Item 9 and 10 ask about the tutees' learning results. The mean of the two items receive a mean just about 4 , which indicates that the tutors had great expectations about the tutees' learning results and they hoped the tutees could study harder. Fourth, item 21 ask about whether the tutors felt pressure in the tutoring program. The mean of the item is three, which shows that they do have some pressure. Lastly, Item 11 to Item 20 ask about the tutors' perceptions about the tutor-tutee relationship and interactions, the tutoring atmosphere, and the tutors' instructional attitudes, and the tutees' learning attitudes. The means of these items are above four.

\section{The Qualitative Data}

In this study, we investigated university students' tutoring and instructional strategies as they worked with junior high students. Several key findings emerged from the data. The following discussions are organized according to research questions and the findings.

\section{Learning to be a teacher}

For most of the participants, this was the first time they learned to teach a student. Playing the role of an online tutor is just like being a teacher. Most of the participants were in the teacher education 
program. It was the tutoring experience that they launched their teaching career, a very small step. The following statements show how they reflected on their teaching skills and strategies.

I have learned to change from the role of student to the role of teacher.... the importance of being a teacher, how to guide the student to learn, and how to motivate him to learn. (\#6)

This semester, in the tutoring program, trying to teach on my own is really a big challenge. Shifting from the role of a student to the role of a teacher, I need to adjust myself in teaching. From not knowing how to teach in the beginning to the present situation of good interactions with the tutee, I gained a lot in teaching. (\#17)

\section{What are tutors'difficulties?}

While there were teaching moments that went well for the tutors, we were most interested in where they experienced difficulty. Our findings from the novice tutors provide important information about their limited understanding of course content and difficulties in applying the teaching strategies in their beginning tutoring sessions. One common aspect we found in the tutors' expressions and journal writing was the tutees' learning attitudes and styles. Tutors expressed frustrations when encountering the tutees' distraction during the class. The tutors often focused on getting the tutees to learn more enthusiastically.

However, the tutees might not follow the planned activities successfully. Thus, the tutors would feel frustrated and they had to implement other strategies to guide the tutees to learn. The following statements show the tutors' concerns.

My tutee feels absent-minded very often and did not concentrate much on learning, which made me feel most frustrated. Sometimes I feel his performance is the same although he did change once or twice, becoming concentrated and responding to me. (\#9)

I did not prepare interesting materials so the tutee felt bored easily. My tutee did not like learning English so he got absentminded very often. I had to remind him to pay attention to his learning attitude, otherwise he was not learning at all. (\#3)

In the beginning, the tutee was not very active in learning and our relationship was very distant. I tried to encourage him and gradually the relationship was improved. (\#16)

Just as we need to know where our tutors experience success, we also need to understand where our tutors experienced difficulty and frustrations. The above statements offer significant clues for use to examine the tutors' weakness. As teacher educators, we need to help the tutors overcome their difficulties and apply strategies to cope with the struggling situations. We need to help them to include more teaching techniques and activities to help tutees to learn more successfully.

\section{What is the tutors' sense of achievement?}

Examining the data, the researchers find the tutors feel their sense of achievement in the following aspects: Seeing tutees' learning progress of English, successfully motivating the tutees to learn, establishing positive tutor-tutee relationships, and receiving good feedbacks from the tutees. Some examples are shown below:

My tutee likes to be in my tutoring session. She gains fruitful results in the tutoring sessions. (\#14)

He was very shy in the beginning of the tutoring sessions, but later, he began to start the topic to share his life with me. After I became acquainted with the tutee, he became interested in learning and with active attitudes. His progress in the academic performance greatly reflected in his monthly test, which made me feel sense of achievement. (\#8)

There was one session my tutee was very attentive in class. $\mathrm{He}$ responded to all my questions and gave me feedbacks. I was very happy and felt touched by his responses. (\#9)

I am very thankful that I have the chance of tutoring a seven grader this semester. His enthusiastic attitudes toward learning especially make me feel sense of achievement. I hope soon he can find his interest and dream in his life. (\#16)

According to Vygotsky (1978), learners progress through successive "zones of proximal development," guided by the more advanced peers. Based on Vygotsky's theories, effective learning does not occur in a vacuum but in collaboration with more capable others. In the online tutoring program, the tutees are guided to learn English by the advanced English learners. The tutors first serve as the language partners for the tutee in the language learning process. They then provide the academic support (Simpson, 2002) for the tutees, which deals with supporting them with the knowledge issues related to the specific courses.

\section{Providing academic and non-academic support}

Just as Simpson (2002) describes, there are two broad areas of tutor support: academic and non-academic. In this study, tutors felt sense of achievement when they saw their academic and non-academic support work for the tutees. When the tutees improved their academic performance and shared their good results in their coursework, the tutors felt their sense of achievement. Similarly, when the tutees shared with the tutors about their personal lives and information outside the school, the tutors felt they had successfully built the relationship with the tutees. Here are two examples:

My tutee is very attentive in the tutoring class. She takes notes during every session and is concentrative. I show consideration for her learning and care about her, asking about her life. She tells me about her life very naturally. (\#18)

I think my tutee loved to share his life with me. In the tutoring, he was willing to listen to my advice. I used the break time to chat about life and to share ideas with him. This made me know that a teacher cannot just teach the course content but also needs to care about students. (\#14)

\section{Developing teaching expertise}

We know that teacher expertise is the critical variable in instruction. Effective teachers demonstrate instructional adaptability, provide explicit instruction, know their teaching goals, and can articulate their purpose for using a particular strategy. Learning to teach 
online is even more complex than face-to-face instruction and preparing tutors to develop this teaching expertise is thus necessary. Novice tutors need to develop a deep understanding of the process of teaching English, demonstrate an ability to adjust instruction, and develop a sense of efficacy to apply what they know when working with individual students. Here are some examples showing how tutors developed their teaching skills:

I am very glad that I got the chance to tutor this semester. My tutee would ask me questions very actively and paid great attention in class. He liked to learn words from articles. I would also prepare different types of teaching materials. (\#12)

In doing oral practice, I would encourage her [my tutee] to read and speak on her own first. If she did not say words correctly, I reminded her about the mistakes. I did not correct her directly so as not to discourage her. (\#1)

In the beginning, I prepared too much course content and taught too much. Later, I learned to decrease some. Then, my student could learn almost $80 \%$ of my materials. (\#12)

In the beginning, I only knew how to take the clipart from the textbook CD to prepare the teaching material. Later, I added some supplementary materials to teach. I have my teaching style. I feel the sense of achievement. (\#13)

Learning to tutor online is more complex than face-to-face tutoring as online tutoring requires computer skills and knowledge in coping with technical problems, not just dealing with educational interactions. Our research has helped us to clearly understand more about the dynamics of the online tutoring and it has also helped add to the literature describing the characteristics of online English tutors. This understanding of what tutors can accomplish in tutoring as well as the problems they may encounter can help teacher educators and researchers better facilitate and scaffold online tutors to develop strong pedagogical knowledge as well as develop their confidence as effective tutors in the future projects.

\section{Summary}

The study examines the university students' tutoring experiences. What have the tutors learned in the tutoring sessions? The researchers find the tutors learned to reflect on their teaching, know how to motivate the tutees to learn, create positive learning atmosphere, build good relationships, make teaching materials suitable for their tutees, being patient, being sympathetic, and understand more about themselves. The following example provides a very good example, describing how our university students gained from the tutoring experience.

I think the online tutoring program provides a great opportunity for university students' personal development. (\#18)

\section{CONCLUSION}

It is common to see problems arise in any innovative program or novice course and this online tutoring course is no exception. Some specific issues emerged concerning the tutees' learning attitudes and the tutors' expertise. Firstly, the tutees' learning attitudes are an important factor influencing the tutors' instruction and their teaching passion. Tutees participating in the afterschool program come from a variety of backgrounds, including academic performances, family economic statuses, and personality traits. Thus, it may be helpful to first equip the tutors with teaching strategies to cope with the tutees and the directors of both the tutors and tutees have to pay more attention when monitoring the tutor-tutee relationship in the tutoring process. Secondly, examining the aspect of learning activities with other aspects, the researcher found tutors needed to pay more attention to designing tutoring activities. This issue would also be related to the tutees' learning attitudes and interest, and results. Thus, offering solutions to help motivate the tutees to learn should be a priority for future projects. In fact, course materials and the teacher play the two most important roles in learning. If the materials cannot stimulate the students' interest in learning, the learning results and students' attitudes would be negatively affected, no matter how excellent the tutor may be. The skills required to successfully teach online teens is not the same as that required to successfully teach on-site. To strengthen the field of online tutoring, it behooves researchers and educators to prepare the tutors with better pedagogical knowledge and skills needed to ensure their competence. Efforts need to be made to instill subject knowledge and skills for high-quality tutoring programs. Thirdly, some tutors had joined the tutoring programs for a couple of semesters. Their expressions demonstrated their expertise in the online tutoring program. In the future project, senior tutors can be invited to share their experiences and materials to help novice tutors. Also, training sessions of designing activities can be offered during the project. Furthermore, a learning community can be form: Tutors can brainstorm ideas about activities and share materials.

The findings of this study have important implications for theory, policy, practice, and future research. Learning to be a teacher or a tutor is not an easy task and success won't come over night. The pedagogical dimensions of tutoring quality may deserve more attention in the conceptualization of tutoring quality, the tutor characteristics, and the supports provided to develop effective tutors. Our data can suggest several fruitful avenues for future researchers. A possible direction for future research is an analysis of the specific skills, knowledge, and abilities associated with effective tutoring.

\section{STUDY LIMITATIONS}

Our study has several limitations that stem from resource constraints. First, we examined the tutoring experiences in this online afterschool program, which does not allow us to generalize to all online tutoring programs in the local context or around the world. Second, we surveyed only the tutors in our English tutoring program. Thus, it is possible that our responding tutors do not represent the experiences of all tutors in other content areas, such as Mathematics or language arts. Third, the data were based on self-reported perceptions from surveys and journals. Including data through first-hand observations and interview might provide more insights. Finally, this is a case study that examines university students' learning in an online tutoring program in one semester. It is suggested that full impact of tutoring may be better measured over time. 


\section{REFERENCES}

Hampel, R., \& Hauck, M. (2004). Towards an effective of audio conferencing in distance language courses. Language Learning $\mathcal{E}$ Technology, 8(1), 66-82. Retrieved from http://lit.msu.edu/vol8num1/hampel/default.html

Lentell, H. (2003). The Importance of the tutor in open and distance learning. In A. Tait \& R. Mills (Eds.), Rethinking learner support in distance education (pp. 64-76). London: Routledge Falmer. https://doi.org/10.4324/9780203464403
Lincoln, Y. S., \& Guba, E. G. (1985). Naturalistic Inquiry. Newbury Park, CA: Sage Publications. https://doi.org/10.1016/01471767(85)90062-8

Ryan, S., Scott, B., Freeman, H., \& Patel, D. (2000). The virtual university: The Internet and resource-based learning. London: Kogan Page Limited.

Simpson, O. (2002). Supporting students in open and distance learning (2 ed.). London: Kogan.

Vygotsky, L. (1978). Mind in society: The development of higher psychological processes. Cambridge, Mass.: Harvard University Press.

\section{APPENDIX A}

\section{The Questionnaire}

1. The tutoring program helped me learn how to help students to learn English. (Mean: 4.53)

2. I felt satisfied at my tutoring skills. (Mean: 3.58)

3. My teaching method helped the tutee to learn English. (Mean: 3.84)

4. My teaching materials were beneficial to the tutee. (Mean: 3.95)

5. I felt satisfied at my teaching materials. (Mean: 3.79)

6. The materials I used could attract my tutees' learning interests. (Mean: 3.74)

7. I prepared different types of teaching activities. (Mean: 3.90)

8. I think my tutee felt satisfied at my teaching activities. (Mean: 3.74)

9. I helped my tutee to master the area he/she was weak. (Mean: 4.05)

10. After this semester's tutoring, my tutee's English was improved. (Mean: 4.05)

11. During the tutoring, I would encourage my tutee to learn English. (Mean: 4.37)

12. During the tutoring, my tutee asked me questions when he/she did not understand. (Mean: 4.37)

13. I had good interactions with my tutee. (Mean: 4.58)

14. My tutee felt comfortable to ask me questions. (Mean: 4.48)

15. I think my tutoring atmosphere was good. (Mean: 4.32)

16. I felt satisfied at my tutoring in this semester. (Mean: 4.26)

17. I was attentive in my tutoring. (Mean: 4.48)

18. My tutee was attentive in tutoring. (Mean: 4.32)

19. I felt satisfied at my tutees' learning attitudes. (Mean: 4.37)

20. I think this semester's tutoring was beneficial to the tutee's English learning. (Mean: 4.32)

21. I felt pressure in the tutoring program. (Mean: 3 )

22. The tutoring program helped me learn about English teaching. (Mean: 4.37) 